PROCEEDINGS, Twenty-Third Workshop on Geothermal Reservoir Engineering Stanford University, Stanford, Califomia January 26-28, 1998 SGP-TR-158

\title{
WATER ADSORPTION AT HIGH TEMPERATURE ON CORE SAMPLES FROM THE GEYSERS GEOTHERMAL FIELD
}

\section{Miroslaw S. Gruszkiewicz, Juske Horita, John M. Simonson and
Robert E. Mesmer \\ Miroslaw S. Gruszkiewicz, Juske Horita, Jo
Robert E. Mesmer

Oak Ridge National Laboratory, Chemical and Analytical Sciences Division P.O. Box 2008

Oak Ridge, TN 37831-6110, U.S.A

xuk@ornl.gov

\section{ABSTRACT}

The quantity of water retained by rock samples taken from three wells located in The Geysers geothermal reservoir, California, was measured at 150,200, and $250{ }^{\circ} \mathrm{C}$ as a function of pressure in the range $0.00 \leq \mathrm{p} / \mathrm{p}_{0} \leq 0.98$, where $\mathrm{p}_{0}$ is the saturated water vapor pressure. Both adsorption (increasing pressure) and desorption (decreasing pressure) runs were made in order to investigate the nature and the extent of the hysteresis. Additionally, low temperature gas adsorption analyses were performed on the same rock samples. Nitrogen or krypton adsorption and desorption isotherms at $77 \mathrm{~K}$ were used to obtain BET specific surface areas, pore volumes and their distributions with respect to pore sizes. Mercury intrusion porosimetry was also used to obtain similar information extending to very large pores (macropores). A qualitative correlation was found between the surface properties obtained from nitrogen adsorption and the mineralogical and petrological characteristics of the solids. However, there is in general no proportionality between BET specific surface areas and the capacity of the rocks for water adsorption at high temperatures. The results indicate that multilayer adsorption rather than capillary condensation is the dominant water storage mechanism at high temperatures.

\section{INTRODUCTION}

The decline in reservoir pressures observed at The Geysers after a period of rapid development (Barker, 1992) prompted an increase in research aimed at a better understanding of the reservoir physics and improving the technology of recovery of geothermal energy so that the life of the reservoir can be sustained for the most economical exploitation of the resource. It is expected that adsorption can affect the response of the reservoir under both production of steam and injection of water in the wells where the pressure fell significantly below its original level in the undisturbed reservoir.

The uptake of water by a porous solid is often called adsorption, regardless of what mechanism of solidfluid interaction is involved. Possible mechanisms of water storage include micropore filling, cooperative adsorption (involving interactions between adsorbate molecules), monolayer and multilayer adsorption, capillary condensation, and interactions similar in varying degrees to chemical bonding. The occurrence of any of these mechanisms depends on the chemical composition of the solids, temperature, pore sizes and shapes, and the way the pores are filled or emptied. Since physical models developed to describe these phenomena are different, it would be desirable to determine the prevailing water storage mechanism at reservoir temperatures, so that an adequate description can be developed. One of the reasons for measuring adsorption isotherms over a range of temperatures is to be able to distinguish between capillary condensation and multilayer adsorption. This distinction is possible because multilayer adsorption isotherms as a function of the relative pressure $p / p_{0}$ are expected to change only very little with temperature, while capillary condensation is temperature dependent. The creation of an adsorption layer and condensation into bulk liquid are thermodynamically very similar processes. Since the associated enthalpy changes and volumetric properties are nearly the same, $p / p_{0}$ at a particular extent of adsorption is expected to remain constant with temperature. According to the established view of physical adsorption caused by dispersion forces, even one layer of adsorbed molecules is able to screen nearly completely the subsequent layers from interactions with the solid surface, so that all but the first, (or at most also the second) layers can be treated as a uniform bulk liquid phase. Although such a model is a simplification, and the adequacy of these 


\section{DISCLAIMER}

This report was prepared as an account of work sponsored by an agency of the United States Government. Neither the United States Government nor any agency thereof, nor any of their employees, makes any warranty, express or implied, or assumes any legal liability or responsibility for the accuracy, completeness, or usefulness of any information, apparatus, product, or process disclosed, or represents that its use would not infringe privately owned rights. Reference herein to any specific commercial product, process, or service by trade name, trademark, manufacturer, or otherwise does not necessarily constitute or imply its endorsement, recommendation, or favoring by the United States Government or any agency thereof. The views and opinions of authors expressed herein do not necessarily state or reflect those of the United States Government or any agency thereof. 


\section{DISCLAIMER}

Portions of this document may be illegible electronic image products. Images are produced from the best available original document. 
assumptions may not be obvious (Barrer et al., 1952), it has been the basis of the most widely used treatments of multilayer adsorption, and it has been included in both the traditional, kinetic (Bnunauer et $a l ., 1938$ ), and the statistical-mechanical (Hill, 1946) derivations of the BET equation, as well as the Frenkel-Halsey-Hill (FHH) equation (Halsey, 1948). The BET parameter $c$ expresses the energetic difference between adsorption directly on the solid surface and adsorption of all the subsequent layers, including the second.

In contrast to multilayer adsorption, the vapor pressure over capillary condensate should be strongly affected by temperature as predicted by the Kelvin equation (Defay et al., 1966):

$\ln \frac{p}{p_{0}}=-\frac{4 K(T)}{d}$

where $K(T)=\frac{\gamma(T) V_{m}(T)}{R T}$,

and where $d$ is the pore diameter, while $\chi(T)$ and $V_{m}(T)$ are the surface tension and the molar volume of the adsorbate, respectively. Both $\chi(T)$ and $V_{m}(T)$ are temperature dependent. In fact, the surface tension of any fluid decreases to zero as the temperature approaches the liquid-vapor critical point. At constant temperature, however, it is difficult or impossible to distinguish between various adsorption mechanisms by considering the observed relation between the relative pressure and the amount of adsorbate present in the pores. Usually adsorption isotherms can be satisfactorily described either in terms of the Kelvin equation or the BET equation. The Kelvin equation approach is expected to deteriorate continuously as pore sizes decrease towards molecular dimensions. Hsieh and Ramey (1978) noticed that experimental data are sometimes described in the literature using the capillary condensation model and the Kelvin equation at the conditions where capillary condensation is no longer conceivable. They suggested that the multilayer adsorption model (and the BET equation) would provide a more appropriate description. Even at the conditions where capillary condensation certainly occurs, a substantial amount of the adsorbate may be more properly described in terms of the multilayer adsorption concept.

The greatest difficulty in the description of porous or fractured solids is that their properties with respect to interaction with fluids vary strongly with geometric configurations and shapes of the pores. In rocks this diversity is compounded by heterogeneity and varying mineral compositions, so that no simple classification of the properties of porous rocks is possible. One of the interesting phenomena inherent in the interactions between porous solids and fluids is the adsorption/desorption hysteresis, which is very commonly observed in the relation between the pressure and the amount of adsorbate for a wide variety of porous adsorbent-adsorptive pairs. The presence of hysteresis makes the application of experimental results somewhat ambiguous, since without knowledge of the history of the system, only a range of values of liquid saturation of the solid can be inferred at a given relative pressure.

Studies of high temperature water adsorption in porous materials have been rather scarce (Shang et al., 1995). The temperatures did not exceed $150^{\circ} \mathrm{C}$, with most of the reported measurements done at $120^{\circ} \mathrm{C}$ and below. Recently, Bertani et al. (1996) reported adsorption (but not desorption) isotherms on several geothermal reservoir rocks at temperatures between $170{ }^{\circ} \mathrm{C}$ and $200{ }^{\circ} \mathrm{C}$. They found no temperature dependence of the amount of water adsorbed in this temperature range. Shang et al. (1995) found an increase in the amount of water adsorbed as the temperature increased from $80^{\circ} \mathrm{C}$ $130^{\circ} \mathrm{C}$. This increase was more pronounced at high relative pressures. They attributed this behavior to either a temperature-dependent chemical equilibrium or the presence of solutes in the adsorbate.

This project was undertaken in order to expand our understanding of the adsorption/desorption processes occurring in rocks found in geothermal reservoirs, with the intention of improving the efficiency of the recovery of geothermal energy through improved inputs to geothermal reservoir models. The main goals were:

- to measure water sorption by the reservoir rocks from The Geysers geothermal field, California, at temperatures close to the actual reservoir conditions $\left(240^{\circ} \mathrm{C}\right)$ and to explore the temperature dependence of adsorption;

- to investigate the hysteresis behavior;

- to characterize the rocks included in the study with respect to water adsorption capacity;

- to investigate the possibility of predicting this capacity using available properties of the rocks. Such properties as porosity, BET specific surface area, total pore volume and pore volume and area distributions with respect to pore size can be obtained by methods that are faster and less expensive than high temperature water adsorption measurements.

The reservoir pressure is an important parameter, as it affects directly the economics of - energy 
production. The rates of both pressure and flow rate decline during production are used as an indicator of the size of the resource and the expected life and performance of the reservoir (Sanyal et al., 1992; Enedy, 1992). Since the steam pressure in vapordominated geothermal reservoirs in their undisturbed state is found to be essentially the saturation pressure of liquid water at the measured reservoir temperature, the reservoir must contain some amount of free water present in wide pores and fractures (Pruess and O'Sullivan, 1992). It was determined that the initial pressure at the sea level in the central part of The Geysers reservoir was 35.4 bars (Lippmann et al., 1978), which corresponds to a boiling temperature of $243.3^{\circ} \mathrm{C}$. This temperature is close to measured well temperatures. The steam drawn from such a reservoir comes initiaily from the evaporation of the excess liquid water. After the reserve of this bulk liquid is exhausted, the water retained in smaller pores and adsorbed on the surfaces starts to evaporate, and the pressure starts to decline. The process of depletion of a steamdominated reservoir assuming thermodynamic equilibrium over all the volume of a closed system is shown schematically in Figure 1.

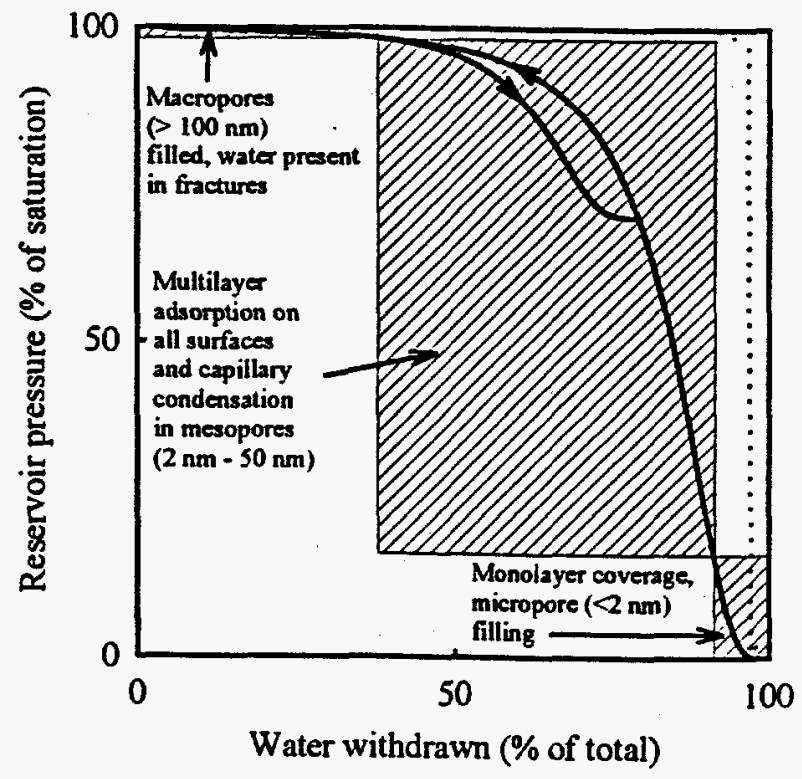

Fig. 1. Equilibrium pressure decline during depletion of a vapor-dominated geothermal reservoir.

Actual response of the reservoir may not follow the adsorption isotherm if the production rate is higher than the relaxation rate of the reservoir, or if the reservoir is being recharged by meteoric or other water. The flat (nearly horizontal) part of the solid curve in Fig. 1 indicates that it is impossible to accurately estimate the amount of water present initially in the reservoir by measuring the reservoir pressure decline, since the withdrawal of large amounts of water at this stage is associated with a immeasurably small long-term decline in equilibrium pressure. In the later stages of the reservoir operation, the amount of water left in the reservoir can be determined in principle from reservoir pressure data, if the water retention capacity as a function of pressure and the reservoir size are known.

As seen in the schematic representation in Fig. 1, the reservoir pressure observed with adsorption present (solid curve) will be lower than the pressure in the hypothetical case without adsorption (dotted curve) for the later stages of the reservoir operation. If any mechanism of lowering water activity is operating (either interactions with solid surfaces or with dissolved substances) a gradual decline in pressure will be observed instead of an abrupt fall to zero when all the water is withdrawn. Since the decline in pressure tends to slow down further depletion, pressure lowering acts as a mechanism stabilizing geothermal reservoirs, delaying a complete dry-out. No matter how closely this reflects the physical reality, this behavior can be explained by the presence of a 'capillary suction' which keeps the moisture inside the rocks at the conditions where liquid water could not exist. The increased interest in adsorption properties of geothermal reservoir rocks is then parallel to the increased interest in the behavior of vapor-dominated geothermal reservoirs in the later stages of their exploitation, when the pressure is substantially lower than the saturation pressure at the nominal reservoir temperature, but the reservoir still contains a considerable amount of water held by the solid-liquid interactions. The knowledge of adsorption characteristics can help in better understanding of the reservoir's response to water injection. The time needed for the injected water to reach the production wells may be longer with adsorption since the injected water will at first readsorb on the surface of fractured rocks in the amount depending on local conditions at the injection well. The amount of water needed during injection may be different from the amount of water previously withdrawn, due to hysteresis.

\section{EXPERIMENTAL}

\section{Samnles}

The measurements were performed on core samples of rocks taken from the productive steam reservoir at The Geysers. Well numbers and approximate depths were as follows: 
- MLM-3, $1322 \mathrm{~m}$

- Prati State 12, $1909 \mathrm{~m}$ (rubble)

- NEGU-17, $2600 \mathrm{~m}$.

The rocks were fine to medium grained graywacke which had been intensely hydrothermally altered during the time the reservoir was liquid-dominated, and the calcite, originally present in veins, was largely replaced by calc-silicates (Hulen et al., 1991, 1992). Hydrothermal mineralization, alteration, mineral dissolution, and fracturing are the causes for the significant porosity and permeability of the reservoir rocks in comparison with the caprock (Gunderson, 1992).

The mineral compositions of the metagraywacke samples taken from the three wells were more diverse than expected. The percentages of the component minerals are given in Table 1.

Table 1. Mineral percentages of the metagraywacke samples (Hulen, 1997).

\begin{tabular}{c|ccc} 
& MLM-3 & NEGU-17 & PS-12 \\
\hline quartz & 38 & 19 & 45 \\
albite & 30 & 16 & 21 \\
chlorite & 14 & 31 & 13 \\
illite & 11 & 14 & 4 \\
epidote & 1 & 2 & 11 \\
adularia & traces & 8 & 3 \\
sphene + anatase & 2 & 2 & 2 \\
calcite & 2 & - & traces \\
ferroaxinite & - & 2 & - \\
organic & 2 & 6 & 1
\end{tabular}

All three core samples contained traces of actinolite, apatite, and zircon, and traces of rutile were found in the MLM-3 and NEGU-17 cores. Additionally, prehnite was found in the MLM-3 sample, and pyrite, garnet, and clinopyroxene were found in the Prati-State sample. The compositions shown in Table 1 indicate that the fine grained NEGU-17 metagraywacke differs significantly from the other two more coarse grained samples in the relative amounts of quartz, albite, and chlorite. NEGU-17 also contains much more organic matter. The core from the Prati State 12 well contains more quartz and epidote but less illite than either NEGU-17 or MLM-3.

The rocks were crushed using a jaw crusher and ground to obtain the fine fraction using a disk attrition mill. The product was separated by screening into three fractions with the following grain sizes: $2.00-4.25 \mathrm{~mm}$ ('coarse'), $0.355-2.00$ mm ('medium'), and $0-0.355 \mathrm{~mm}$ ('fine'). Two aliquots of each of the medium fractions were loaded in the autoclave in order to evaluate possible random differences due to the heterogeneity of the samples.

After completing the measurements it was discovered that some amount of iron (steel) particles originating from the disk mill was present in the fine fraction samples. Estimated weight fraction of iron was at least several per cent. Since the steel particles were smaller than $0.355 \mathrm{~mm}$, they passed quantitatively into the fine fractions, but the coarse and medium fractions did not contain noticeable impurity iron.

\section{Annaratus}

The ORNL high-temperature isopiestic apparatus has been described previrusly. (Holmes et al., 1978; Gruszkiewicz et al., 1996). Briefly, the samples were placed inside a high-pressure, high-temperature autoclave in titanium pans fitting in holes in a disk which was rotated by the operator. The pans were positioned in turn on the torsion suspension electromagnetic balance and weighed in situ by adjusting the electric current through the balance coil. The mass of a sample was proportional to the current required to bring the balance beam back to the null point. Since each weighing is made by comparison with a set of standard weights placed inside the pressure vessel together with the samples, the method's susceptibility to significant systematic errors is greatly reduced.

In addition to the high temperature water adsorption measurements, low temperature $(77 \mathrm{~K})$ nitrogen adsorption and desorption isotherms were determined by Micromeritics laboratories (Norcross, Georgia). Nitrogen adsorftion runs were made in the whole relative pressure $\left(p / p_{0}\right)$ range from 0.01 to above 0.99 and desorption runs (for selected samples) from 0.99 back to 0.14. Multipoint BET specific surface area analyses and pore size distributions were obtained from these data. Adsorption results were supplemented with mercury intrusion tests on selected samples, also done by Micromeritics. Mercury intrusion results provided information about wide pores which are beyond the useful range of the Kelvin equation, and at the same time practically all mesopore sizes were included. The mercury pressure scans extended from 0.11 bar to $4.14 \mathrm{kbar}$, providing a nominal pore diameter range from $114 \mu \mathrm{m}$ to $3 \mathrm{~nm}$. 


\section{RESULTS}

\section{Reliability}

It was determined that the relatively large irreversible water retention reported previously (Gruszkiewicz et al., 1996), and thought to be due to the hydration of some of the minerals, was most likely an experimental artifact due to the oxidation of the iron originating from the milling process. Taking this into account, the increase in water adsorption observed for the fine grain size fractions was in fact moderate, as could be expected from the increase in the specific surface area due to the reduction in grain size. For example, the BET specific surface areas were $2.45 \mathrm{~m}^{2} / \mathrm{g}$ and $1.31 \mathrm{~m}^{2} / \mathrm{g}$ for the fine and medium grain size fractions of MLM-3. The differences in BET specific surface areas (or water adsorption capacities) between the coarse and medium fractions were less than the random variability between the samples

In general, the capacities for water adsorption of the cores taken from the three wells were consistently in the order MLM-3 > NEGU-17 > Prati-State 12. The differences between the twin medium fraction aliquots of the same rock were small for MLM-3 and NEGU-17, but quite significant for Prati-State 12.

Since the properties of the rocks vary significantly with depth, it is normally not possible to compare directly the results obtained in different laboratories, even on samples coming from the same well. However, in one case where the reported depths were nearly the same, the agreement between a $150^{\circ} \mathrm{C}$ adsorption isotherm on the MLM-3 coarse grain size sample obtained in this work, and a corresponding $120^{\circ} \mathrm{C}$ isotherm obtained by Satik and Horne (1995) was very good (Gruszkiewicz et al. 1996). However, the agreement of the desorption isotherms was not satisfactory, as the hysteresis loops obtained in this work were closed or nearly closed, while extensive low pressure hysteresis and irreversible water retention were observed by Satik and Horne (1995) and Shang et al. (1995) on all their samples.

\section{Temperature Denendence And Hysteresis}

Figures 2, 3 and 4 show the experimental results for water sorption on the medium fractions of MLM-3, NEGU-17 and Prati-State 12 rocks, respectively, at 150,200 and $250^{\circ} \mathrm{C}$.

In all the figures open symbols represent experimental results on the adsorption branches, and filled symbols represent desorption branches. The 200 and $250{ }^{\circ} \mathrm{C}$ isotherms were shifted upwards along the ordinate axis to avoid overlapping (all the

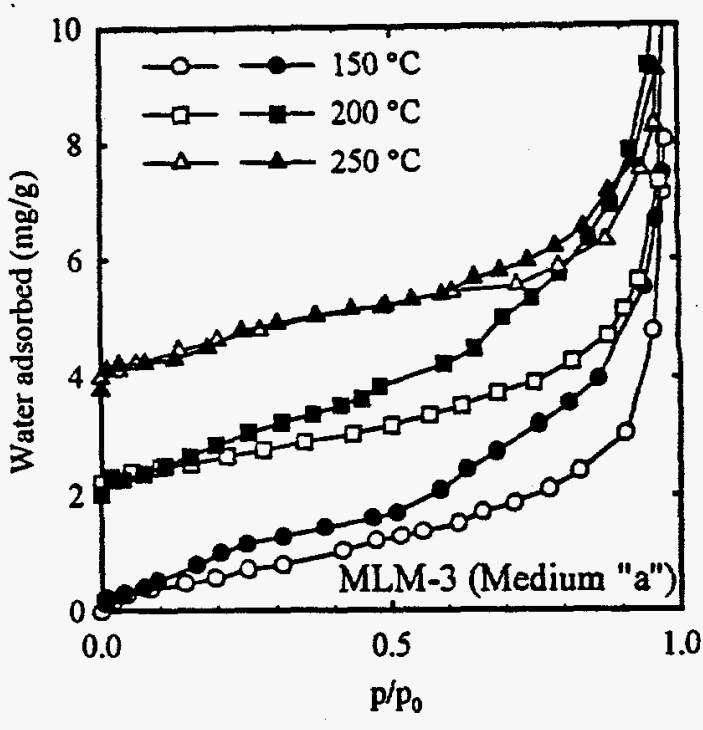

Fig. 2. Adsorption and desorption isotherms of water on the medium grain size fraction of the MLM3 core samples. An offset of 2 and $4 \mathrm{mg} / \mathrm{g}$ was added to the 200 and $250^{\circ} \mathrm{C}$ isotherms, respectively.

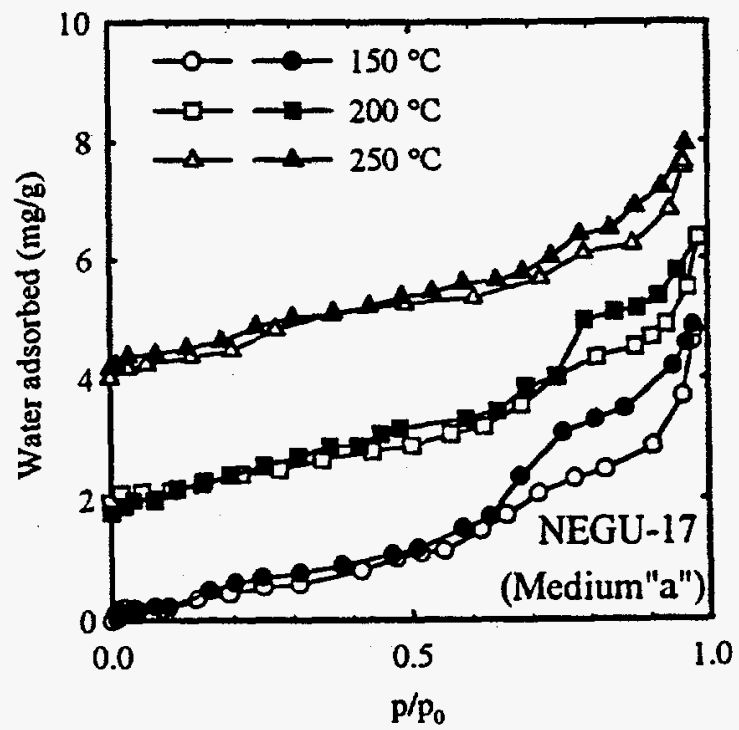

Fig. 3. Adsorption and desorption isotherms of water on the medium grain size fraction of the NEGU-17 core samples. An offset of 2 and $4 \mathrm{mg} / \mathrm{g}$ was added to the 200 and $250^{\circ} \mathrm{C}$ isotherms, respectively.

isotherms start at a water content close to zero). The following features of physical adsorption of water on the rocks investigated can be seen in Figures 2, 3, and 4:

- There is essentially no temperature dependence of the adsorption branches; 


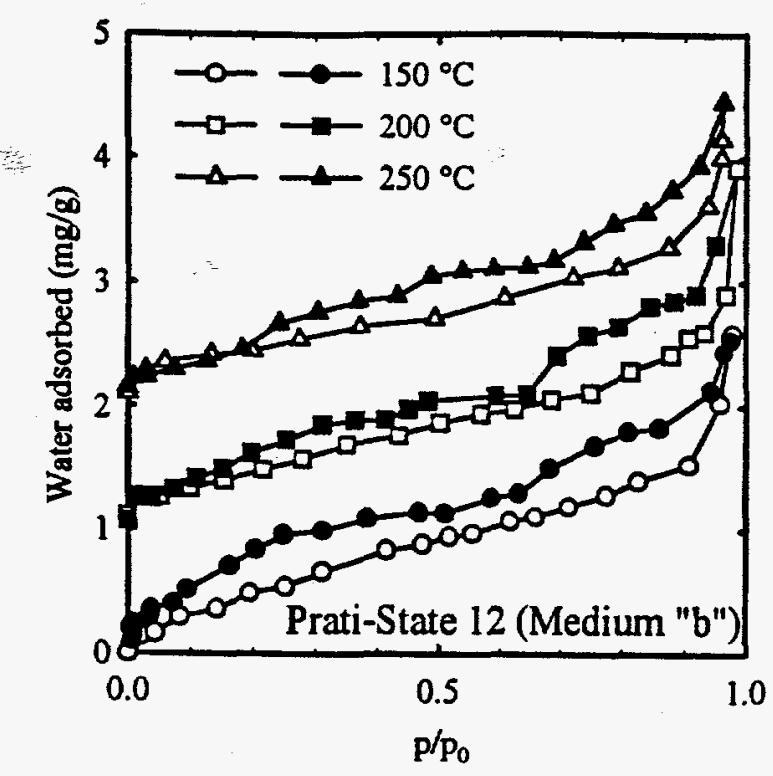

Fig. 4. Adsorption and desorption isotherms of water on the medium grain size fraction of the Prati State 12 core samples. . An offset of 1 and $2 \mathrm{mg} / \mathrm{g}$ was added to the 200 and $250{ }^{\circ} \mathrm{C}$ isotherms, respectively.

- As the temperature increases the hysteresis loop shrinks in both the amount of the adsorbate and the pressure range (this is most clear in the NEGU-17 isotherms);

- Water adsorption is reversible (the mass of the sample in vacuum after an adsorptiondesorption cycle remains the same), but;

- The hysteresis loops persist to very low pressures in the case of MLM-3 and Prati-State 12, while distinct closure points at an intermediate pressure are present for NEGU-17. The closure points for the 'main' hysteresis loop due to capillary condensation are also visible in MLM-3 and Prati-State 12 isotherms.

What is the origin of hysteresis in adsorption/ desorption? The different mechanisms of adsorption and desorption are usually pictured in the following way, called the 'delayed meniscus theory' (Arnell and McDermott, 1957). As the relative pressure increases, multilayer adsorption occurs continuously on all the walls. Capillary condensation starts at lower pressures in the small pores, and at higher pressures in the large ones, beginning only after the free diameter has decreased sufficiently because of the adsorbate present on the walls. When desorption starts as the pressure declines from saturation, with all the pores initially full, the only available vaporization mechanism is evaporation from the menisci. The menisci will not disappear at the same relative pressures as when they were formed, but usually at lower pressures. As a result, the average curvature of the liquid surface during adsorption and desorption will be different (it will approach that of the cylindrical free spaces inside the pores for adsorption, and that of the spheroidal menisci, for desorption). It should be noted, however, that hysteresis also occurs in non-porous adsorbents, and other possible causes for adsorption/desorption hysteresis both in porous and non-porous solids may exist. Explanations which do not invoke different mechanisms of filling and emptying the pores may rely on the presence of unstable regions and phase transitions in the adsorbate (Hill, 1947; Arnell and McDermott, 1957; Greg and Sing, 1982, p. 126).

While on the adsorption branch the water may be present both as multilayer adsorbate and as capillary condensate, in principle all of the excess retention on the desorption branch may be due to capillary condensation. This explains why water retention on the desorption branch changes with increasing temperature, while the adsorption branch is nearly temperature independent. Both the pressure range of the hysteresis loop and the excess water retention should decrease with increasing temperature if the Kelvin equation is obeyed. An analysis of the Kelvin equation (1) and the functions $X(T)$ and $V_{m}(T)$ for water indicates that the relation between the relative pressure $\mathrm{p} / \mathrm{p}_{0}$ and the temperature at constant pore diameter $d$ is approximately linear. For example, the capillaries smaller than $d=2 \mathrm{~nm}(20 \AA)$ should be filled with water at relative pressures equal to at least

$$
\left(\frac{p}{P_{0}}\right)_{2 \mathrm{~nm}}=0.297+0.00187(T-298.15 \mathrm{~K}),
$$

where $T$ is the temperature. It is reasonable to assume that capillary condensation and the hysteresis associated with it do not occur in capillaries smaller than about $2 \mathrm{~nm}$. Liquid menisci cannot exist in very small, molecular-size capillaries, where the interactions of all the adsorbate molecules with the solid surface are strong. In other words, the relative pressure corresponding to the inception point of the hysteresis (the low pressure limit of the hysteresis loop) should change with temperature roughly in the same way as the relative pressure corresponding to some small capillary diameter calculated from the Kelvin equation. The hysteresis loop inception points determined experimentally at $150{ }^{\circ} \mathrm{C}$ and $200^{\circ} \mathrm{C}$ for NEGU-17 agree well with corresponding relative pressures calculated from equation 2. At $250^{\circ} \mathrm{C}$ the hysteresis loops are narrow, and the inception points are not well defined. The inception point calculated from equation 2 at $250^{\circ} \mathrm{C}$ is $\mathrm{p} / \mathrm{p}_{0}=0.76$, so that the hysteresis can be present only on the steep part of the 
isotherm, where it is hard to detect. Simultaneously, the excess water present on the desorption branch is decreasing as the surface tension decreases with temperature. As a result, the hysteresis loop nearly collapses at $250^{\circ} \mathrm{C}$, as seen in Fig. 2, 3 and 4 .

Since the mechanism of water retention on the adsorption branch is mainly multilayer adsorption, with a heat effect similar to that of condensation into bulk water, there is little or no change with temperature of the amount of water adsorbed this way. It appears that only a very small fraction of water is adsorbed as capillary condensate on MLM-3 and Prati-State 12 samples. Capillary condensation is more visible in NEGU-17 samples (Fig. 3).

The causes for the low-pressure hysteresis (Fig. 2 and 4) on very heterogeneous rock samples are difficult to identify with certainty. It has been known (Arnell and McDermott, 1957) that swelling of some sorbents, caused by the presence of adsorbates, can lead to low-temperature hysteresis as new surface sites open up during desorption. It was recently suggested (Tvardovski et al., 1997) on the basis of dilatometric measurements that sorbent deformation is more common than was previously thought and might be a universal cause for (low pressure) sorptive hysteresis, since it occurs to a detectable extent even in materials with a rigid structure. Nevertheless, in addition to adsorbate-induced structural changes, other causes for low-temperature hysteresis have been proposed. Irreversible hydroxylation of surfaces certainly can cause hysteresis across the relative pressure range (Gregg and Sing, 1982, p. 270). Low-pressure hysteresis of water on calcite was observed by Gregg and Gammage (1972) and attributed to practically irreversible penetration of water deep into molecularsize crevices between adjacent surfaces of the lamellar solid, from where it can escape only very slowly. Finally, dissolution of the solid in the adsorbent can probably cause both positive and negative hysteresis, depending on whether new adsorption sites are created or destroyed. The components most likely responsible for the low pressure hysteresis observed in the altered graywacke are chlorite and other clay-like minerals, or calcite.

\section{Pore Svstem Properties And Rock Compositions}

The differences between water and nitrogen molecules have an impact on the measured adsorption isotherms and specific surface areas determined from nitrogen and water adsorption. It is known that a porous material's capacity for water adsorption can be either larger or smaller than its capacity for nitrogen adsorption, depending on the nature of the adsorbent. (Gregg and Sing, 1982, p.

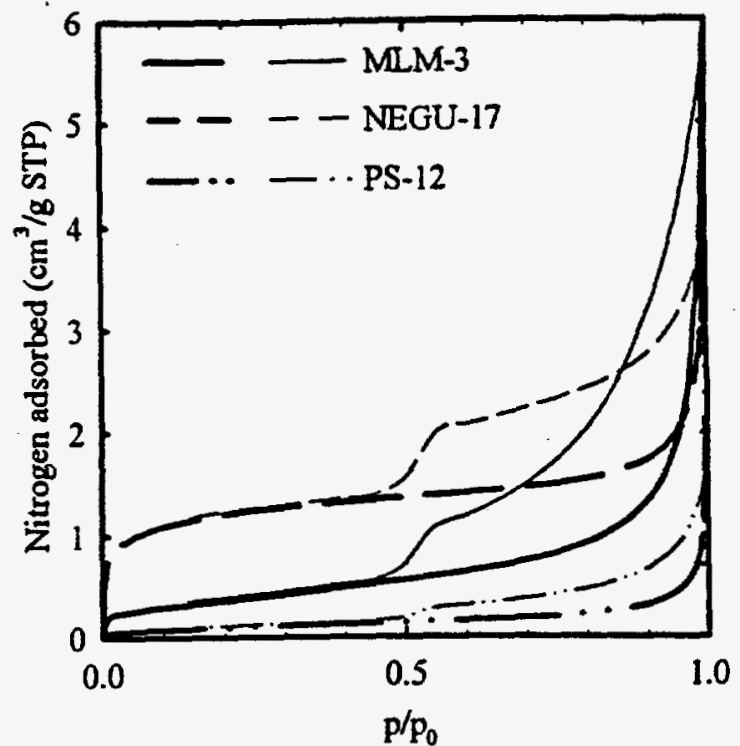

Fig. 5. Adsorption and desorption isotherms of nitrogen at $77 \mathrm{~K}$ on the medium grain size fractions of the three cores investigated.

238). All the nitrogen adsorption isotherms obtained in this work had well defined hysteresis loops closing at $\mathrm{p} / \mathrm{p}_{0} \approx 0.45$ (a rather typical value for nitrogen at temperatures close to its boiling point). Nitrogen adsorption (bold lines) and desorption (regular lines) isotherms for medium grain size samples of the three cores investigated are shown in Fig. 5 .

The following characteristics of the samples can be seen in this diagram:

- There are large differences in the amounts adsorbed by the three cores (the ratios MLM-3 : NEGU-17 : Prati-State 12 at $p / p_{0}=0.4$ are 1 : $2.56: 0.29$; the BET specific surface areas are $1.31,4.06$, and $0.36 \mathrm{~m}^{2} / \mathrm{g}$, respectively);

- NEGU-17 metagraywacke has the largest specific surface area and its pore area distribution is shifted towards smaller pores compared to the other two cores;

- The MLM-3 metagraywacke adsorbs the largest amount of nitrogen at high pressures, which is likely due to the presence of more macropores.

Fig. 6 (below) shows water adsorption isotherms of the three cores (averages of the medium and coarse fractions) at $200^{\circ} \mathrm{C}$. The following characteristics of water adsorption, in contrast to nitrogen adsorption are evident from a comparison of Figures 5 and 6:

- The increase in the amount of the adsorbate in the very low pressure range corresponding to the monolayer formation is small in comparison 


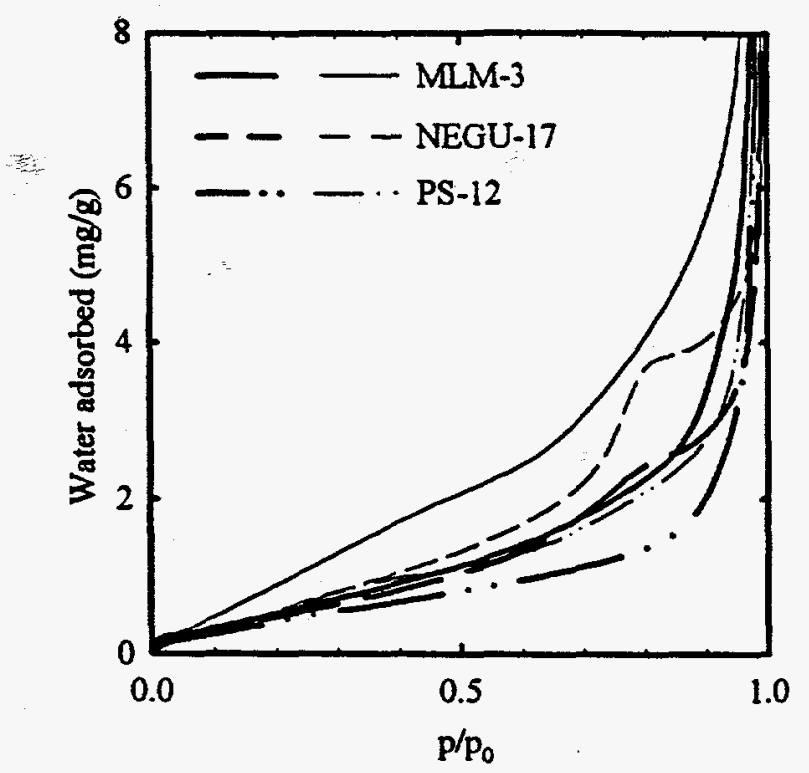

Fig. 6. Adsorption and desorption isotherms of water at $200{ }^{\circ} \mathrm{C}$ averaged for all the coarse and medium grain size fractions of the three cores investigated (the amounts of water retained at $p / p_{0}=0$, if any, were subtracted).

with the increase in the intermediate pressure range when subsequent layers are added. This indicates that solid-fluid interactions are relatively weaker (as compared to the fluid-fluid interactions) for water than for nitrogen. As a consequence, molecular-size pores (which are still wide enough to admit either $\mathrm{N}_{2}$ or $\mathrm{H}_{2} \mathrm{O}$ molecules) are filled more easily with nitrogen than with water. In the latter case the energetically favorable hydrogen bonding network cannot exist in the adsorbed phase to the extent possible in bulk liquid. For this reason, the interaction with solid surface is less advantageous energetically to polar, hydrogenbonding capable molecules, than it is to simple molecules.

- In contrast to nitrogen adsorption, the amounts of water retained by the three cores at low relative pressures are similar (the ratio MLM-3 : NEGU-17 : Prati-State 12 at $p / p_{0}=0.4$ is 1 : $0.90: 0.74$

- The NEGU-17 isotherm has a distinctly different shape from the other two isotherms.

Figures 5 and 6 show that the standard BET surface areas cannot be used directly to predict relative capacities of various rocks for water adsorption, even if the materials are similar rocks. There is convincing evidence, obtained by all three methods (high temperature water adsorption, low temperature nitrogen adsorption, and ambient temperature mercury intrusion), indicating that NEGU-17 metagraywacke has significantly more micropores and also fewer very wide macropores than either MLM-3 or Prati-State 12. Pore volume distributions calculated from both nitrogen and water adsorption isotherms show a distinct difference between NEGU17 and the other two cores. Average pore diameters (27.2, 6.6, and $28.6 \mathrm{~nm}$ for MLM-3, NEGU-17, and Prati-State 12, respectively) calculated from nitrogen adsorption BET surface areas and total pore volumes also indicate that NEGU-17 metagraywacke has a finer pore structure than the other two cores. The average pore diameter for NEGU-17 calculated using the Langmuir specific surface area analysis was even lower $(4.7 \mathrm{~nm})$.

Both nitrogen adsorption and mercury intrusion results indicated that changes in the pore structure had taken place during the high temperature adsorption experiments. Pore volume distributions showed a shift towards wider pore sizes in NEGU-17 and MLM-3 samples, while Prati-State 12 pore volume distribution remained unchanged. Since the smallest pores are most affected by changes occurring on the surface or by solid dissolution and subsequent deposition, the Prati-State 12 metagraywacke apparently has by far the fewest very narrow pores. Partial dissolution of the finest crystals and sealing of the finest pores was also indicated by the decreases of 20 to 30 per cent in the BET specific surface areas and increases in the average pore sizes obtained both by nitrogen adsorption and mercury intrusion for all the rock samples where such measurements were made before and after the high temperature steam exposure. In a sample of silica gel the fine pore structure was nearly completely destroyed upon exposure to steam even at $150^{\circ} \mathrm{C}$, and the specific surface area decreased from 542 $\mathrm{m}^{2} / \mathrm{g}$ by the BET method, or $782 \mathrm{~m}^{2} / \mathrm{g}$ by the Langmuir method to $3.0 \mathrm{~m}^{2} / \mathrm{g}$ (BET). This was likely due to the dissolution of $\mathrm{SiO}_{2}$ in adsorbed water, but not by recrystallization of quartz, which was not detected by X-ray diffractometry. Similar effects can be expected to occur, to a lesser extent, in reservoir rocks containing crystalline silica and other minerals which are increasingly soluble in water at elevated temperatures. Since there is a significant random variability between the samples, obtaining definitive evidence for these changes would require more tests performed on exactly the same aliquots before and after high temperature adsorption measurements.

Total pore volumes (and hence total porosities) are difficult to measure unambiguously by either adsorption or mercury intrusion. The adsorption isotherms of rock samples are characterized by a steep increase of the amount of water retained with the increase in pressure towards saturation, so that 
the isotherm is apparently asymptotic to the $p / p_{0}=1$ axis. Such behavior is not universal in porous materials, since often a plateau at high relative pressures is found. The lack of a plateau indicates that the pore volume distribution is relatively even in the upper end of the pore size range, and there is no distinct upper pore size limit. The shape of adsorption/desorption isotherms similar to those obtained in this study is often observed with aggregates of plate-like or sheet-like particles giving rise to slit-shaped pores and is referred to as type $\mathrm{H3}$ isotherm (Sing et al., 1985). This shape of the pores is also compatible with porosity caused by fracturing and bulk crystallization. Since the widest pores may contribute significantly to the total volume (although usually not to the total surface area), this limits the accuracy of total pore volume determinations. In the case of nitrogen adsorption measurements, the accuracy of temperature and pressure measurement and control at the boiling point of nitrogen limits the useful pore diameter range to at most $200 \mathrm{~nm}$ with extremely accurate work. The uncertainty in the upper pore size limit exists also in mercury intrusion measurements where the initial filling pressure will determine the distinction between internal and external volumes of a sample. Of course, in the lower limit of pore sizes mercury intrusion results are less reliable and there is a possibility of sorbent deformation under high pressure. The porosity results $(8.4,10.9$ and $12.3 \%$ in the sequence NEGU17, Prati-State 12, and MLM-3) are significantly higher than those reported by Satik et al. (1996) for similar materials (up to 5.5 per cent for MLM-3 metagraywacke) or by Gunderson (1990) (1.1 to 5.6 per cent for NEGU-17 core of approximately the same depth as in this work). With proper procedures the average density of the rock solids can be determined fairly accurately (it is $2.75-2.78 \mathrm{~g} / \mathrm{cm}^{3}$ for the samples included in this work, with a maximum error of about 2 per cent), but even here we encountered quite inaccurate helium pycnometry determinations. The main difficulty in finding porosities by the mercury intrusion method seems to lie in measuring the total volumes of the porous rocks. The differences in mercury intrusion procedures (immersion pressure), sample grain sizes, and random differences between the samples can significantly impact total porosity results.

The differences in adsorption properties between MLM-3, NEGU-17, and Prati-State 12 cores are consistent with the differences in mineral compositions (Table 1). Enhanced microporosity of the NEGU-17 samples is concomitant with a more than doubled fraction of chlorite and the largest fraction of organic matter. Chlorite is a mineral related chemically to montmorillonite and other clay minerals which form charged molecular layers able to interact with each other and to form stable structures involving water molecules (Barrer and Reay, 1957). The strength of such interactions is intermediate between that of dispersion forces and typical chemical bonding. On the other hand, quartz and feldspars, which constitute more than 65 per cent of the MLM-3 and Prati-State 12 samples, but only 45 per cent of the NEGU-17 samples, have more rigid, three dimensional structures, which do not accommodate water or small cations as easily. (Their surfaces, however, can be found in different hydroxylation states.) The highly carbonized organic matter found in the NEGU-17 samples might be contributing to the observed microporosity and hydrophobic adsorption, as would charcoal (Gregg and Sing 1982, p. 262). A more detailed study focusing on the properties of the constituent minerals could lead to more precise assignments of the contributions to the observed adsorption behavior, which would be useful for predicting adsorption properties of rocks.

\section{ACKNOWLEDGMENTS}

Research sponsored by the Geothermal Division, Office of Energy Efficiency and Renewable Energy, and the Division of Chemical Sciences, Office of Basic Energy Sciences, US Department of Energy, under contract DE-AC05-96OR22464 at Oak Ridge National Laboratory operated by Lockheed Martin Energy Research Corporation.

\section{REFERENCES}

Arnell, J. C. and McDermott, H. L. (1957) Sorption hysteresis. In Proceedings of the Second International Congress on Surface Activity, Vol. 2, pp. 113-121, Butterworths, London.

Barker, B. J., Gulati, M. S., Bryan, M. A. and Riedel. K. L. (1992) Geysers reservoir performance. In Monograph on The Giysers geothermal field, ed. C. Stone, pp. 167-177. Geothermal Resources Council Special Report No. 17.

Barrer, R. M., Mackenzie, N. and MacLeod, D. (1952) The adsorption method of measuring surface area. J. Chem. Soc. 1736-1744.

Barrer, R. M., Reay, J. S. S. (1957) Interlamellar sorption by montmorillonite. In Proceedings of the Second International Congress on Surface Activity, Vol. 2, pp. 113-121, Butterworths, London.

Bertani, R, Parisi, L., Perini, R. and Tarquini, B. (1996) High temperature adsorption measurements. In Proceedings of the $21^{s t}$ Workshop on Geothermal Reservoir Engineering, pp. 523-529, January 24-26, Stanford University, Stanford, CA. 
Brunauer, S., Emmett, P. H. and Teller, E. (1938) Adsorption of gases in multimolecular layers. J. Am. Chem. Soc., 60, 309-319.

Defay, R., Prigogine, I., Bellemans, A. and Everett, D. H. (1966) Surface tension and adsorption. p. 218, Longmans, London.

Enedy, K. L. (1992) The role of decline curve analysis at The Geysers. In Monograph on The Geysers geothermal field, ed. C. Stone, pp. 197-203. Geothermal Resources Council Special Report No. 17.

Gammage, R. B. and Gregg, S. J. (1972) The sorption of water vapor by ball-milled calcite. $J$. Colloid Interface Sci., 38, 118-124.

Gregg, S. J. and Sing, K. S. W. (1982) Adsorption, Surface Area and Porosity, Academic Press, San Diego, CA.

Gruszkiewicz, M. S., Horita, J., Simonson, J. M. and Mesmer, R. E. (1996) Measurements of water adsorption on The Geysers rocks. In Proceedings of the $21^{\text {st }}$ Workshop on Geothermal Reservoir Engineering, pp. 481-487, January 24-26, Stanford University, Stanford, CA.

Gunderson, R. P. (1992) Porosity of reservoir graywacke at The Geysers. In Monograph on The Geysers geothermal field, ed. C. Stone, pp. 89-93. Geothermal Resources Council Special Report No. 17.

Halsey, G. (1948) Physical adsorption on nonuniform surfaces. J. Chem.Phys., 16, 931-937.

Hill, T. L. (1946) Statistical mechanics of multimolecular adsorption. I. J. Chem. Phys. 14, 263-267.

Hill, T. L. (1947) Statistical mechanics of multimolecular adsorption. III. Introductory treatment of horizontal interactions. Capillary condensation and hysteresis. J. Chem. Phys. 15, 767777.

Holmes, H. F., Baes Jr., C. F. and. Mesmer, R. E. (1978) Isopiestic studies of aqueous solutions at elevated temperatures. J. Chem. Thermodynamics, 10, 983-996.

Hsieh, C.-H. and Ramey H. J. Jr. (1978) An inspection of experimental data on vapor pressure lowering in porous media. Geothermal Resources Council, Transactions, 2, 295-296.

Hulen, J. B., Walters, M. A. and Nielson, D. L. (1991) Comparison of reservoir and caprock core from the Northwest Geysers steam field, Califomia - implications for development of reservoir porosity. Geothermal Resources Council, Transactions, 15, 11-18.

Hulen, J. B., Nielson, D. L. and Martin, W. (1992) Early calcite dissolution as a major control on porosity development in The Geysers steam field, California - additional evidence in core from Unocal well NEGU-17. Geothermal Resources Council, Transactions, 16, 167-174.

Hulen, J. B. (1997) Personal communication.

Lippmann, S. C., Strobel, C. J. and Gulati, M. S. (1978) Reservoir performance of The Geysers field. Geothermics, 7, 209-219.

Pruess, K. and O'Sullivan, M. (1992) Effects of capillarity and vapor adsorption in the depletion of vapor-dominated geothermal reservoirs. In Proceedings of the $17^{\text {th }}$ Workshop on Geothermal Reservoir Engineering, pp. 165-174, January 29-31, Stanford University, Stanford, CA.

Sanyal, S. K., Mezies, A. J., Brown, P. J., Enedy, K. L. and Enedy, S. L. (1992) A systematic approach to decline curve analysis for The Geysers steam field, California. In Monograph on The Geysers geothermal field, ed. C. Stone, pp. 189-196. Geothermal Resources Council Special Report No. 17.

Satik, C., Horne, R. N. (1995) Experimental data published at the Stanford Geothermal Program site on the World Wide Web (http://ekofisk.stanford.edu /geotherm.html).

Satik, C., Walters, M. and Horne, R. M. (1996) Adsorption characteristics of rocks from vapordominated geothermal reservoir at The Geysers, CA. In Proceedings of the $21^{s t}$ Workshop on Geothermal Reservoir Engineering, pp. 469-479, January 24-26, Stanford University, Stanford, CA.

Shang, S., Horne, R. N. and Ramey, H. J. (1995) Water vapor adsorption on geothermal reservoir rocks. Geothermics 24, 523-540.

Sing, K. S. W., Everett, D. H., Haul, R. A. W., Moscou, L., Pierotti, R A., Rouquérol, J. and Siemieniewska, T. (1985) Reporting physisorption data for gas/solid systems with special reference to the determination of surface area and porosity. Pure and Appl. Chem. 57, 603-619.

Tvardovski, A. V., Fomkin, A. A., Tarasevich, Yu. I. and Zhukova, A. I. (1997) Hysteresis phenomena in the study of sorptive deformation of sorbents. $J$. Colloid Interface Sci.191, 117-119. 